\title{
Autologous Stromal Vascular Fraction Containing Stem Cells Combined with Low Intensity Shock Wave for the Treatment of Human Erectile Dysfunction
}

\section{Elliot B Lander* and Mark H Berman}

Cell Surgical Network, Rancho Mirage, California, USA

\begin{abstract}
Objective: This study seeks to determine whether the addition of autologous Adipose-Derived Stem Cells (ADSCs) may safely synergize with the clinical effects of Low-Intensity Shock Wave Therapy (LIST) to improve Erectile Dysfunction (ED) in a small series of men.

Methods: Under IRB protocols, 52 patients with multifactorial ED were treated with LIST immediately followed by a single intracavernosal injection of lipoaspirate derived autologous Stromal Vascular Fraction (SVF). Human SVF derived using our protocols has been shown to contain Mesenchymal Stem Cells (MSCs) and Hematopoietic Stem Cells (HSCs). Subjective outcomes testing with the International Index of Erectile Function (IIEF) Score and Erectile Hardness Score (EHS) were administered to the patients at baseline and every 3 months for 2 years. All patients were queried for adverse reactions and all outcomes were self-reported.
\end{abstract}

Results: Excellent safety was seen and none of the patients experienced any adverse reactions related to LIST or harvesting and deployment of SVF. A retrospective review of efficacy indicated that 37 out of 52 patients $(71 \%)$ responded positively to the question of whether they experienced "overall improvement" after their treatment. Mean IIEF reference questionnaire scores and Mean Erectile Hardness Grading Score (EHS) were also reported by patients. Mean IIEF scores went from 10.21 baseline to 18.40 at 6 months $(p=0.0008)$. Mean EHS scores improved from 1.34 baseline to 2.17 at 6 months $(p=0.012)$.

Conclusion: Intracavernosal deployment of autologous SVF combined with low-intensity acoustic shock wave therapy to the penis appears to be safe and may offer some benefits to a cross-section of patients who suffer from ED. Larger trials are indicated to identify which types of stem cells are optimal, which subsets of ED patients appear to benefit the most, and which types of shock wave protocols yield the best results.

Keywords: Low-intensity shock wave therapy; Stromal vascular fraction; Stem cells; Erectile dysfunction; Clinical research

Abbreviations: ADSCs: Adipose-Derived Stem Cells; LIST: Low-Intensity Shock wave Therapy; ED: Erectile Dysfunction; SVF: Stromal Vascular Fraction; MSCs: Mesenchymal Stem Cells; HSCs: Hematopoietic Stem Cells; IIEF: International Index of Erectile Function; EHS: Erectile Hardness Score

\section{Introduction}

Low-Intensity Shock Wave Therapy (LIST) has recently gained wide attention in the urologic community for its potential effects in improving ED [1-8]. Shock waves appear to stimulate vascular flow and erectile function and one possible mechanism of action are through an endogenous stem cell-mediated regenerative effect $[9,10]$. Assuming that endogenous progenitor cells are implicated in vascular repair and proliferation there might exist an opportunity for synergizing LIST with augmented numbers of autologous stem cells deployed into the corporal target tissues to amplify the regenerative effect.

Stem cell therapy alone for ED is starting to gain attention but the marketing appears to have outpaced the science. There have been numerous animal studies in the literature since 2004 dealing with the use of various progenitor cells deployed in different ways to improve erectile tissue histology or function, with the vast majority demonstrating positive results [11-13]. The number of human publications on the effects of cellular therapy on ED is extremely low considering that $\mathrm{ED}$ is prevalent in more than 30 million men in the United States alone [14-21].
We report on 52 patients with ED who received a concurrent combination of shock wave therapy and intracavernosal injection of autologous SVF (rich in MSCs and HSCs) from human lipoaspirate. SVF is a heterogeneous population of cells obtained from the enzymatic digestion of lipoaspirate. SVF composition generally includes ADSCs, similar in morphology to adult MSCs, HSCs, endothelial progenitor cells, pericyte progenitor cells, macrophages, red blood cells, platelets, and T-regulatory cells, and various growth factors [22]. There is extensive veterinary experience mostly for orthopedic purposes of positive outcomes in safely treating animals with SVF [23]. Using recent technologic advances, we are currently able to isolate autologous SVF from adipose tissue in a sterile, rapid, surgically "closed" system in the operating room or clinic and deploy the product back into patients during the same surgical setting.

Adult Stem Cells were serendipitously identified in lipoaspirate in 2001 [24] and were originally used by plastic surgeons in conjunction

*Corresponding author: Elliot B Lander, Cell Surgical Network, Rancho Mirage, California, USA, Tel: 760-346-0145; Fax: 760-776-0041; E-mail: elliot@cellsurgicalnetwork.com

Received August 03, 2018; Accepted September 11, 2018; Published September 17, 2018

Citation: Lander EB, Berman MH (2018) Autologous Stromal Vascular Fraction Containing Stem Cells Combined with Low Intensity Shock Wave for the Treatment of Human Erectile Dysfunction. Stem Cell Res Ther 8: 438. doi: 10.4172/21577633.1000438

Copyright: (c) 2018 Lander EB, et al. This is an open-access article distributed under the terms of the Creative Commons Attribution License, which permits unrestricted use, distribution, and reproduction in any medium, provided the original author and source are credited. 
with fat as a way to fortify the graft material for improved uptake in reconstructive cosmetic procedures. Yoshimura, et al. [25] have been particularly significant in advancing this concept in Japan and in 2008 coined the term "Cell Assisted Lipo-Transfer." The Cell Surgical Network began using similar technology for procuring SVF in 2010 but focused on therapeutic purposes rather than cosmetic enhancement indications. Since that time, Cell Surgical Network clinical research teams have performed over 9000 procedures under IRB protocols collecting data in an online database for a variety of conditions including orthopedic, neurologic, pulmonary, urologic, cardiac and several other areas including chronic pain and auto-immune diseases.

Flow cytometry was utilized to evaluate the cellular composition of SVF samples on 44 patients not included in this ED study but who underwent identical processing of their lipo-aspirate using the Time Machine protocol. Flow cytometric evaluation was performed using the FACScalibur (BD Biosciences Franklin Lakes, NJ). Cellular analysis showed that freshly isolated SVF was very heterogeneous (as expected with an autologous biologic) and harbored four major subsets of progenitor cells specific to adipose tissue; CD34high CD45CD31- CD146- ADSCs, CD34 low CD45+ CD206+ CD31- CD146HSC-progenitors, CD34high CD45- CD31+ CD146+ adipose tissueendothelial progenitor cells and CD45-CD34-CD31-CD146+ pericytes progenitor cells. The clinical correlations underscore the regenerative role of HSCs since the ratio of mesenchymal ADSC's to HSCs within SVF may impact clinical outcomes [26]. The majority of clinical information on HSCs has traditionally been based on cancer research supporting bone marrow ablation and replacement strategies with the regenerative contributions of HSCs now just coming to light.

There is a plethora of evidence [27-33] based information to suggest that adult MSCs may have a significant beneficial use for a large variety of inflammatory, autoimmune and degenerative conditions. SVF has been used extensively for degenerative orthopedic conditions and arthritis. Michalek [34], from the Czech Republic, reported excellent safety data and very favorable outcomes using intra-articular SVF on 1128 patients evaluated for arthritic conditions. Cell Surgical Network published a safety paper in 2016 on 1524 patients for the safety of SVF deployment over a 5 year period. $97 \%$ of the patients treated also received systemic intravenous therapy in addition to their regional SVF deployment. As in most studies using SVF, safety was shown to be excellent with no severe adverse events related to SVF deployment into the soft tissue [35].

\section{Materials and Methods}

Fifty-two patients with ED of various etiologies but mostly vascular origin received a short weekly series (1-6) of low-intensity acoustic shock waves This IRB approved (International Cell Surgical Society) pilot study evaluated men who met selection criteria for ED due to various etiologies including post-surgical iatrogenic trauma, microvascular disease, diabetes mellitus, and idiopathic. Contraindications to inclusion in the study included age less than 18 , severe coagulopathy, significant concurrent infections, and uncontrolled cancer. Patient's age range was 27-80 (mean 59).

Patients were told that they would be treated with intracavernosal SVF deployment with concurrent LIST and signed IRB approved informed consents emphasizing the investigational nature of their SVF deployments and the "off-label" use of shock wave therapy. All patients underwent history and physical exams prior to their procedures. Serum testosterone and nitric oxide levels were optimized when indicated.

The CSN Time Machine system (USA trade name for the
MediKhan Lipokit system - Los Angeles, CA, USA) was used to harvest, centrifuge, incubate, and isolate the SVF product. To harvest lipo-aspirate, patients underwent sub-dermal (non-tumescent) instillation of an approximately $20 \mathrm{~cm}^{2}$ region of posterior flank skin using local anesthetic consisting of lidocaine $0.5 \%$ with epinephrine 1:400,000 and sodium bicarbonate $8.4 \%$. The patients then received a sterile prep and drape and a mini-liposuction was performed through a \#11 blade puncture wound using a gentle negative pressure syringe technique through a $3 \mathrm{~mm}$ cannula. $50 \mathrm{cc}$ of lipo-aspirate solution was collected in a TP101 syringe (TP-101 syringe by Medikhan, Los Angeles, USA) and condensed by centrifugation at $2800 \mathrm{rpm}$ for $3 \mathrm{~min}$ in the Time Machine centrifuge. Next, 12.5 Wunsch units of T-MAX Good Manufacturing Practices (GMP) grade collagenase (private label name for Liberase by Roche, Indiana, USA) in $25 \mathrm{cc}$ of normal saline was added to $25 \mathrm{cc}$ of condensed lipo-aspirate and incubated at $38^{\circ} \mathrm{C}$ in the Time Machine incubator for $30 \mathrm{~min}$ to digest the collagen matrix in order to procure the SVF in closed Time Machine Syringes (TP-102 syringe by Medikhan, Los Angeles, USA). The product was washed with D5LR Lactated Ringer's solution sequentially three times and then the SVF isolated by concentrating to $10 \mathrm{cc}$ final volume. The entire SVF processing was done in the operating room at the bedside in approximately $80 \mathrm{~min}$. Photomicrography using the Invitrogen by Countess (Invitrogen, ThermoFisher Scientific, Waltham, Ma) was used to document lack of aggregation, count cells, and measure cell viability using $0.4 \%$ trypan blue. Cell viability ranged from $65 \%$ to $95 \%$ with most patients yielding viability ranging from $80 \%-90 \%$. The wide variability in cell viability is customary with the point of care extraction of SVF and is dependent on the susceptibility of the cells to centrifugation. Cell viability did not appear to impact clinical outcomes. Cell count, viability, and dosing varied in SVF in all patients as expected with an autologous biologic product.

While SVF was being prepared for injection, patients received shock wave treatments using the Storz D- Actor machine, (Karl Storz, Tägerwilen, Switzerland) set at $15 \mathrm{~Hz}, 6000$ shocks, 1-2.6 Barr with a 20 $\mathrm{mm}$ radial head and coupling jelly. Shockwaves were delivered along the lateral aspect of the penile shaft just prior to intracavernosal injection of the SVF. A few patients received a short (weekly) series of shocks (1-6) over a 6 week period but the majority received shock treatment only on the day of SVF injection.

Following delivery of the acoustic shocks, a tourniquet was applied to the base of the penis and $10 \mathrm{cc}$ of SVF was injected into one side of the corpora cavernosa. The tourniquet was removed after $20 \mathrm{~min}$.

Patients were followed for adverse events related to lipo-harvesting and penile SVF injection. No serious adverse events were reported to the IRB. Safety and outcomes data were collected via email and telephone and entered into a customized TrackVia (Denver, CO, USA) HIPPA compliant database to protect patient privacy. In most cases, patients electronically self-reported efficacy feedback or adverse outcomes directly to the database to mitigate the potential for a Hawthorne effect (i.e., observer effect on responses). All patients were treated in clinics and by affiliated doctors of the Cell Surgical Network. All affiliated subinvestigator research sites were trained by the authors and used the same devices, techniques, and IRB approved protocols to isolate and deploy SVF and follow outcomes.

\section{Results}

A few patients noted mild ecchymosis and/or transient swelling of the penis after the shock wave and SVF penile injection. The mild soft tissue trauma was self-limited to the first 24 hours in those cases and no 
patient complained of any sustained penile injury. No patients required any form of pain medication post procedure. No long-term adverse events were reported.

All patients received testing with IIEF scores and EHS at baseline and at 6 months and every 3 months for 2 years. Outcomes were assumed significant when $\mathrm{p}<0.05$.

For the EHS (normal is $0-3$ ), scores went from 1.34 at baseline to 2.17 at 6 months (Figure 1). EHS Scores showed a statistically significant improvement that sustained up to 2 years (Figure 2).

For the IIEF Erectile Function Score (Questions \#1,2,3,4,5, and 15 with maximum score $=30$ ), baseline 10.21 increased to 18.40 at 6 months (Figure 3). This also showed improvement even up until 2 years 23.50 (Figure 4).

The IIEF Total Score (Questions \#1-15 with maximum score=70), baseline 31.5 increased to 52.21 at 6 months with statistical significance $\mathrm{p}<0.0001$ (Figure 5).

Overall, 37 out of 52 patients (71\%) reported "yes" to the question of whether there was an overall improvement in erectile function after combined SVF and LIST. None of the other fifteen patients reported worsening of their erectile function after treatment.

\section{Discussion}

There have been several reports describing the combination of adipose-derived MSCs with penile shock wave in a Racine model demonstrating positive effects on the cavernosal tissue [9,36,37]. In one such study, combination treated penile tissue showed significantly increased levels of cavernous nerve beta-III tubulin expression, smooth muscle actin, neural and endothelial NOS nitric oxide synthase, cGMP, and reduced cavernosal apoptotic index [37].

This is the first reported study of the combination of stem cells and shock wave in humans. Fresh autologous SVF containing four

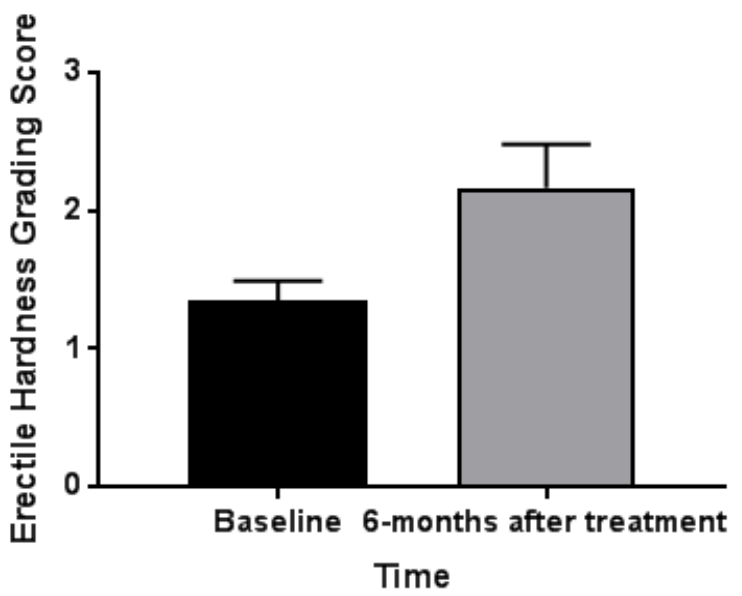

Baseline Mean \pm SEM: $1.344 \pm 0.1458$

6 Month Mean \pm SEM: $2.167 \pm 0.3157$, $\mathrm{n}=52, \mathrm{P}$ value $=0.0116$, Significantly different $(P<0.05)=$ yes

Figure 1: Data is analyzed with paired Student's t-test. Data is presented as Mean \pm SEM.

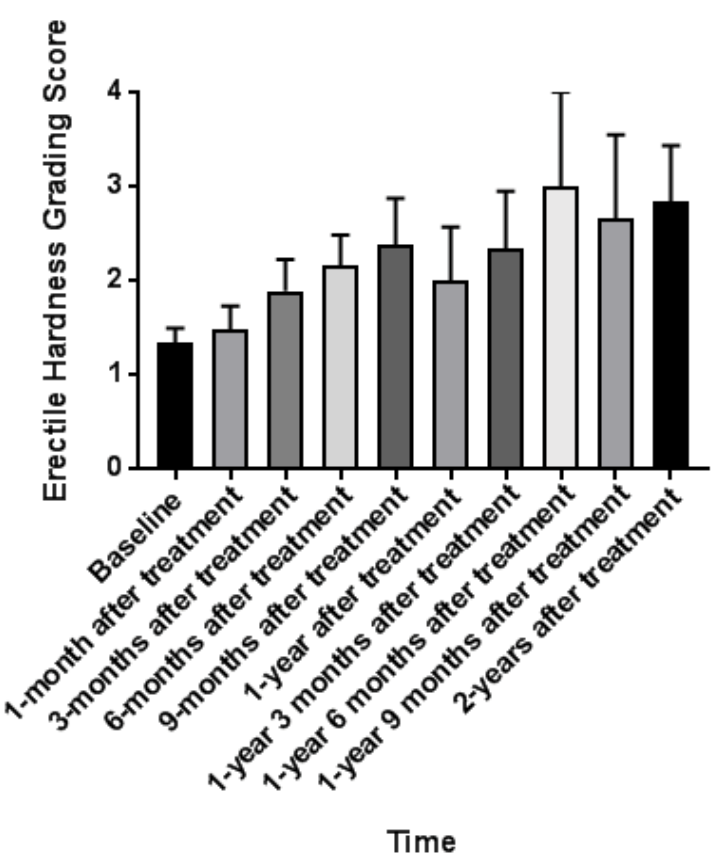

Baseline Mean \pm SEM: $1.344 \pm 0.1458$

1 -month Mean \pm SEM: $1.44 \pm 0.2467$,

3 -month Mean \pm SEM: $1.889 \pm 0.3322$,

1 -year Mean \pm SEM: $2.00 \pm 0.5669$,

$2-y e a r$ Mean \pm SEM: $3.00 \pm 0.6009$

Figure 2: Data is presented as Mean \pm SEM.

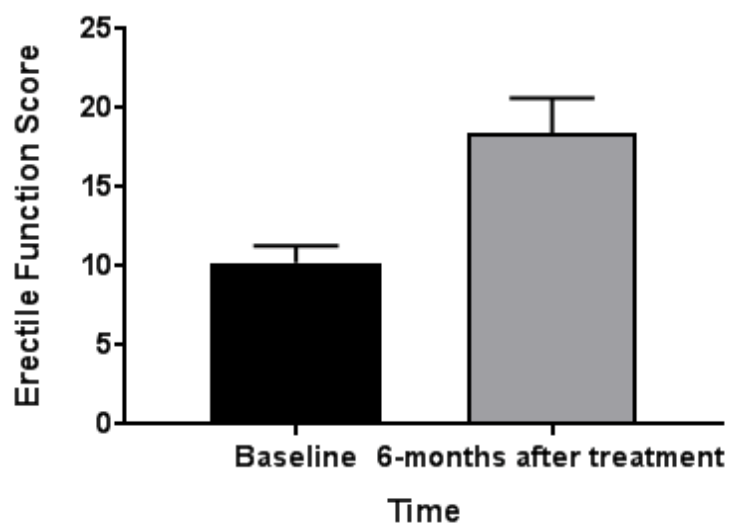

Baseline Mean \pm SEM: $10.21 \pm 1.072$

6 -month Mean \pm SEM: $18.40 \pm 2.248$ $n=52, P$ value $=0.0008$,

Significantly different $(P<0.05)=y e s$

Figure 3: Data is analyzed with paired Student's t-test. Data is presented as Mean \pm SEM

diverse types of progenitor cells has shown tremendous promise as a regenerative therapy. The ADSC population in SVF has demonstrated the ability to differentiate along mesenchymal lines into many other 


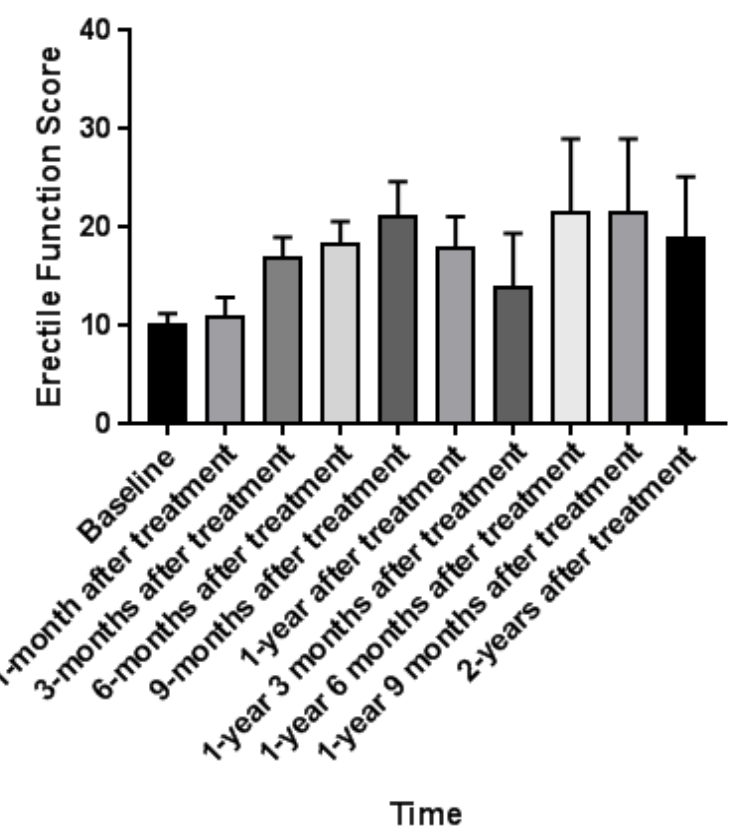

Baseline Mean \pm SEM: $10.21 \pm 1.072$, 1 -month Mean \pm SEM: $10.88 \pm 1.804$ 3 -month Mean \pm SEM: $17.00 \pm 2.00$, 1 -year Mean \pm SEM: $18.00 \pm 3.162$, 2 -year Me an \pm SEM: $23.50 \pm 6.197$

Figure 4: Data is presented as Mean \pm SEM

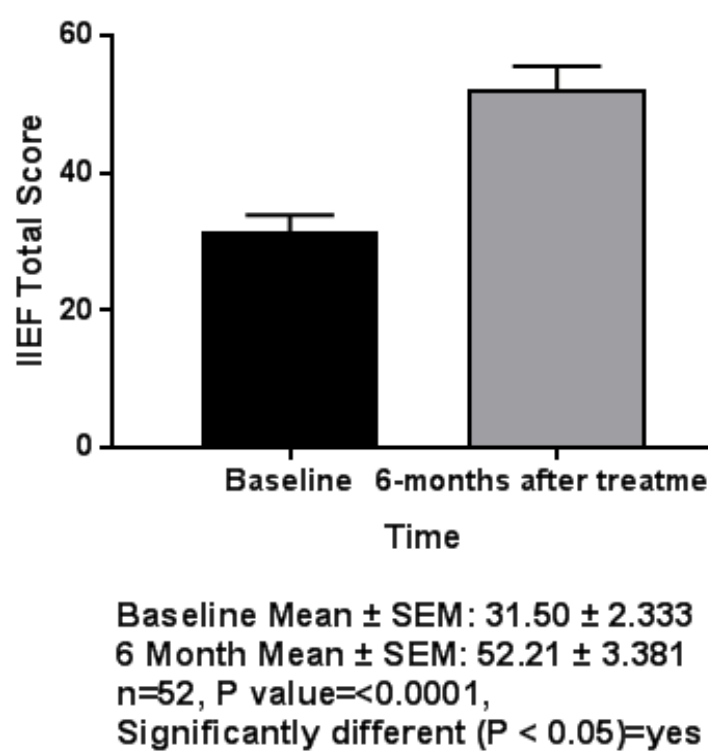

Figure 5: Data is analyzed with paired Student's t-test. Data is presented as Mean \pm SEM

cells and tissues [38]. Endothelial progenitor cells and pericytes are considered precursors of new blood vessels and help promote neovascularization.
Although SVF has shown tremendous potential as a cell therapy in treating arthritis and many autoimmune and neurological conditions, ED presents a unique challenge since much of the efficacy of cell therapy depends on the biologic state of the target tissue. One of the clinical lessons learned after evaluating cell therapy efficacy response in over 9000 patients treated with cell therapy by Cell Surgical Network CSN is that both "cell factors" and "patient factors" influence clinical outcomes. Cell factors may include the cell type, viability, and proliferative quality. Patient factors represent the patient's regenerative micro-milieu. The "patient factor" has a larger impact on clinical outcomes when there are "loud cellular signals" such as severe or acute tissue damage, inflammation or degeneration. Such conditions are more likely to rapidly home and activate stem cells to effect healing. SVF has been shown to significantly enhance recovery of ED in rats with acute cavernosal injury [39]. However, the chronic smoldering relatively quiescent vascular degeneration associated with many cases of ED may not adequately confer these repair signals onto the stem cells. One good example of the patient factor affecting clinical outcomes is with Peyronies disease which often has an early inflammatory component (the "patient factor") and results with SVF combined with shock waves has shown excellent efficacy improving curvature and erectile function in a small pilot study performed by these authors [40].

One further point about cell therapy that should be emphasized is that at least some of the beneficial effects of stem cells on penile vasculature may not be due to direct cellular engraftment and transdifferentiation, but rather the "paracrine" effect of stem cells. The paracrine effect is mediated by complex cell-to-cell communication via several mechanisms which may involve mRNA, micro RNA, exosomal mRNA, and peptide cytokines. This effect has been described in animals where exogenously deployed stem cells appear to migrate physically from the penile tissue to bone marrow but may have prolonged delayed systemic effects on promoting vasculature without direct engraftment [41]

Shock wave therapy has been used extensively on human tissue for various purposes. High-intensity shock wave therapy is used for urinary stone lithotripsy because of its focused mechanical destructive nature. Medium-intensity shock waves have been shown to have anti-inflammatory properties and are used for treating a wide range of orthopedic conditions, such as non-union fractures, tendonitis, and bursitis. Low-intensity shock waves probably have angiogenic properties and are used in the management of chronic wounds, peripheral neuropathy, and in cardiac ischemic tissue [7].

Low-intensity shock waves applied to tissue appear to stimulate endogenous resident MSCs and Schwann cells to repair or form new tissues with blood vessels and nerves [9]. Studies in rats using LIST to treat damaged cavernous nerves demonstrated progenitor cell recruitment, penile angiogenesis, tissue restoration, and penile nerve regeneration including nNOS-positive nerve fibers along with Schwann cell activation and proliferation $[8,42]$. LIST has also been shown to recruit endothelial progenitor cells required for new blood vessel formation in ischemic tissue [10]. LIST has also been shown in vitro to activate cultured Schwann and endothelial penile progenitor cells [9].

The mechanism of action of focused shock waves applied to the targeted deep tissue is the creation of transient micromechanical shear forces that initiate several biological changes [7]. Many of these biologic effects are mediated through signaling molecules in addition to cellular factors. LIST has been shown to stimulate the expression of angiogenesis-related growth factors, such as endothelial Nitric Oxide Synthase (NOS), Vascular Endothelial Growth Factor (VEGF), and endothelial cell proliferation factors, e.g., Proliferating 
Citation: Lander EB, Berman MH (2018) Autologous Stromal Vascular Fraction Containing Stem Cells Combined with Low Intensity Shock Wave for the Treatment of Human Erectile Dysfunction. Stem Cell Res Ther 8: 438. doi: 10.4172/2157-7633.1000438

Page 5 of 6

Cell Nuclear Antigen (PCNA). These factors lead to the induction of neovascularization and cell proliferation [7].

Shock wave may also assist in "homing" stem cells into the penile target tissues. In one animal study of stem cell migration, ADSCs injected into the corpora left the target tissue and migrated to bone marrow within 2 days but then returned to the corpora in response to additional local trauma [41]. Such cell migration phenomena may support the use of repetitive shock wave treatments to keep stem cells supplied to the area for optimal healing. Some of these homing effects may be mediated through stem cell migration to the major pelvic ganglion MPG via SD-1 homing cytokine expression ultimately leading to neuro-regeneration of nerve cell bodies after iatrogenic trauma [43].

Although there is an abundance of recent literature supporting the use of shock wave therapy for ED, there is a lack of consensus on optimal shock wave protocols leading to confusion in the urologic literature since different technologies, power settings, shock counts, and numbers of treatments vary over dozens of studies. Only recently are standardized controlled trials being conducted to evaluate shock wave type, energy used, and optimal delivery schedule.. The result has been that shock waves alone are generally considered promising for ED but standardized protocols are still being developed [44].

One of the limitations of studies evaluating surgical procedures like SVF deployment is the lack of a control arm, but that would require that some patients receive placebo SVF which would constitute a sham surgery. This has ethical implications since the patients have to undergo an invasive surgical procedure to procure their SVF rather than opening a bottle to receive a placebo drug.

Overall, results suggest that many patients with ED who had shock wave therapy combined with SVF injection had positive subjective outcomes suggesting a role for exogenous cell therapy in combination with shock wave therapy. However, at this time, more detailed controlled studies are needed. LIST alone or stem cells alone may contribute independently to positive outcomes for ED adding complexity to the data interpretation on this combined study. Review of world human literature for the use of stem cells alone for ED shows limited efficacy with results generally ranging in the $33-67 \%$ range [15-20].

In this study, $71 \%(37 / 52) \mathrm{ED}$ patients responded to combined SVF and LIST treatment. Although the number of patients enrolled in this study was relatively few, safety was excellent with no serious adverse events related to liposuction, SVF deployment, or shock wave therapy reported. The results suggest that SVF combined with LIST may be helpful in mitigating ED of various causes but larger studies are indicated. The role of shock wave as an added benefit to cell therapy and vice-versa is still not entirely clear but is conceptually appealing and the benefits seem to outweigh any detriments in view of the safety. It will be important to determine if ED of certain etiologies may respond better than others and it is unclear whether SVF is the optimal cell therapy product to combine with shock wave therapy for ED.

Future studies may benefit from utilizing penile vascular studies with ultrasound in addition to subjective outcomes testing which will be useful to better identify objective evidence of erectile improvement. Larger placebo randomized trials are indicated here to better delineate the effects of SVF with shock wave on ED. Further expanded studies to identify optimal shock wave devices, energy settings, and deployment protocols are also needed since such standards are lacking at this point in the science of LIST for ED. This pilot study suggests that intracavernosal deployment of autologous SVF in combination with
LIST is overall safe and well tolerated and may have the potential to play a role in the mitigation of human ED.

\section{Acknowledgment}

We acknowledge the following sub-investigators who participated in protocols and contributed data:

- Johnson B (MD), Innovations Medical Stem Cell Treatment Center, Dallas, Texas

- Chen W (MD), Northern California Regenerative Cell Treatment Center Mountain View, California

- Stevens J (MD), Carolina Stem Cell Treatment Center, Cary, North Carolina

- Barmada H (MD), Mississippi Stem Cell Treatment Center, Ocean Springs, Mississippi

- E. Griffith MD, New Health Regenerative Medicine Center, Lenexa, Kansas Both authors (Elliot B Lander (MD) and Mark H Berman (MD)) have approved the final manuscript

\section{Conflict of Interest}

Dr. Lander and Dr. Berman have an ownership interest in Cell Surgical Network. No other authors have conflicts.

\section{Funding}

This research did not receive any specific grant from funding agencies in the public, commercial, or not-for-profit sectors. Funding provided by Cell Surgical Network.

\section{References}

1. Olsen AB, Persiani M, Boie S, Lund L (2015) Can low-intensity extracorporeal shockwave therapy improve erectile dysfunction? A prospective, randomized double-blind, placebo-controlled study. Scand J Urol 49: 329-333. [PubMed]

2. Perelman J, Hepnar V (2017) Men's Power Pressure Wave Erectile Regeneration-Therapy: an Early Assesment. Urol Nephrol Open Access J 4 00136.

3. Gruenwald I, Appel B, Kitrey ND, Vardi Y (2013) Shockwave treatment of erectile dysfunction. Ther Adv Urol 5: 95-99. [PubMed]

4. Vardi Y, Appel B, Jacob G, Massarwi O, Gruenwald I (2010) Can low-intensity extracorporeal shockwave therapy improve erectile function? A 6-month followup pilot study in patients with organic erectile dysfunction. Eur Urol 58: 243248. [PubMed]

5. Vardi Y, Appel B, Kilchevsky A, Gruenwald I (2012) Does low intensity extracorporeal shockwave therapy have a physiological effect on erectile function? Short-term results of a randomized, double-blind, sham controlled study. J Urol 187: 1769-1775. [PubMed]

6. Chung E, Wang J (2017) A state-of-art review of low intensity extracorporeal shock wave therapy and lithotripter machines for the treatment of erectile dysfunction. Expert Rev Med Devices 14: 929-934. [PubMed]

7. Abu-Ghanem Y, Kitrey ND, Gruenwald I, Appel B, Vardi Y (2014) Penile low-intensity shock wave therapy: a promising novel modality for erectile dysfunction. Korean J Urol 55: 295-299. [PubMed]

8. Li H, Matheu MP, Sun F, Wang L, Sanford MT, et al. (2016) Low-energy Shock Wave Therapy Ameliorates Erectile Dysfunction in a Pelvic Neurovascular Injuries Rat Model. J Sex Med 13: 22-32. [PubMed]

9. Lin G, Reed-Maldonado AB, Wang B, Lee YC, Zhou J, et al. (2017) In Situ Activation of Penile Progenitor Cells With Low-Intensity Extracorporeal Shockwave Therapy. J Sex Med 14: 493-501. [PubMed]

10. Aicher A, Heeschen C, Sasaki K, Urbich C, Zeiher AM, et al. (2006) Low-energy shock wave for enhancing recruitment of endothelial progenitor cells: a new modality to increase efficacy of cell therapy in chronic hind limb ischemia. Circulation 114: 2823-2830. [PubMed]

11. Lin CS, Xin ZC, Wang Z, Deng C, Huang YC, et al. (2012) Stem Cell Therapy for Erectile Dysfunction: a critical review. Stem Cells Dev 21: 343-351. [PubMed]

12. Shan H, Chen F, Zhang T, He S, Xu L, et al. (2015) Stem cell therapy for erectile dysfunction of cavernous nerve injury rats: a systematic review and metaanalysis. PLoS One 10: e0121428. [PubMed] 
Citation: Lander EB, Berman MH (2018) Autologous Stromal Vascular Fraction Containing Stem Cells Combined with Low Intensity Shock Wave for the Treatment of Human Erectile Dysfunction. Stem Cell Res Ther 8: 438. doi: 10.4172/2157-7633.1000438

Page 6 of 6

13. Wang Y, Wang YM, Chen C, Wang YC, Song NH, et al. (2017) Adipose-derived stem cells for the treatment of penile erectile dysfunction: An update. Zhonghua Nan Ke Xue 23: 561-565. [PubMed]

14. Reed-Maldonado AB, Lue TF (2016) The Current Status of Stem-Cell Therapy in Erectily Dysfunction: A Review. World J Mens Health 34: 155-164. [PubMed]

15. Miroshnykov YO, Klunnyk MO, Sych NS, Sinelnyk AA, Sorochynska KI, et al. (2017) 104 Pluripotent Fetal Stem Cells for Treatment of the Vascular Factor of Erectile Dysfunction. J Sexual Med 14: 1-25.

16. Yiou R, Hamidou L, Birebent B, Bitari D, Lecorvoisier P, et al. (2016) Safety of Intracavernous Bone Marrow-Mononuclear Cells for Postradical Prostatectomy Erectile Dysfunction: An Open Dose-Escalation Pilot Study. Eur Urol 69: 988991. [PubMed]

17. Haahr MK, Jensen CH, Toyserkani NM, Andersen DC, Damkier P, et al. (2016) Safety and Potential Efffect of a Single Intracavernous Injection of Autologous Adipose-Derived Regenerative Cells In Patients with Erectile Dysfunction Following Radical Prostatectomy: An Open-Label Phase I Clinical Trial. EBioMedicine 5: 204-210. [PubMed]

18. Levy JA, Marchand M, lorio L, Cassini W, Zahalsky MP (2016) Determining the Feasibility of Managing Erectile Dysfunction in Humans With Placental-Derived Stem Cells. J Am Osteopath Assoc 116: 1-5. [PubMed]

19. Garber MG, Carlos ND (2015) Intracavernous Administration of Adipose Stem Cells: A New Technique of Treating Erectile Dysfunction in Diabetic Patient, Preliminary Report of 6 Cases. MOJ Cell Sci Rep 2: 00018.

20. Bahk JY, Jung JH, Han H, Min SK, Lee YS, et al. (2010) Treatment of diabetic impotence with umbilical cord blood stem cell intracavernosal transplant: preliminary report of 7 cases. Exp Clin Transplant 8: 150-160. [PubMed]

21. El Osta R, Decot V, Bensoussan D, Stoltz JF, Eschwege P, et al. (2018) Treatment by stem cell therapy of erectile dysfunction of diabetic origin: State of the art. Prog Urol 28: 74-84. [PubMed]

22. Riordan NH, Ichim TE, Min WP, Wang H, Solano F, et al. (2009) Non-expanded adipose stromal vascular fraction cell therapy for multiple sclerosis. J Tansl Med 7: 29. [PubMed]

23. Black LL, Gaynor J, Gahring D, Adams C, Aron D, et al. (2007) Effect of adiposederived mesenchymal stem and regenerative cells on lameness in dogs with chronic osteoarthritis of the coxofemoral joints: a randomized, double-blinded, multicenter, controlled trial. Vet Ther 8: 272-284. [PubMed]

24. Zuk PA, Zhu M, Mizuno H, Huang J, Futrell JW, et al. (2001) Multilineage cells from human adipose tissue: implications for cell-based therapies. Tissue Eng 7: 211-228. [PubMed]

25. Yoshimura K, Sato K, Aoi N, Kurita M, Hirohi T, et al. (2008) Cell-assisted lipotransfer for cosmetic breast augmentation: supportive use of adiposederived stem/stromal cells. Aesthetic Plast Surg 32: 48-55. [PubMed]

26. Kilinc MO, Santidrian A, Minev I, Toth R, Draganov D, et al. (2018) The ratio of ADCSs to HSC-progenitors in adipose tissue derived SVF may provide the key to predict the outcome of stem-cell therapy. Clin Transl Med 7: 5. [PubMed]

27. Cayci C, Carlsen BT (2014) Osteoarthritis of the wrist. Plast and Reconstr Surg 133: 605-615. [PubMed]

28. Chang H, Do BR, Che JH, Kang BC, Kim JH, et al. (2013) Safety of adiposederived stem cells and collagenase in fat tissue preparation. Aesthetic Plastic Surg 37: 802-808. [PubMed]

29. Pak J (2011) Regeneration of human bones in hip osteonecrosis and human cartilage in knee osteoarthritis with autologous adipose-tissue-derived stem cells: a case series. J Med Case Rep 5: 296 [PubMed]

30. Pak J, Lee JH, Lee SH (2014) Regenerative repair of damaged meniscus with autologous adipose tissue-derived stem cells. Biomed Res Int 2014: 436029

31. Rodriguez JP, Murphy MP, Hong S, Madrigal M, March KL, et al. (2012) Autologous stromal vascular fraction therapy for rheumatoid arthritis: rationale and clinical safety. Int Arch Med 5: 5. [PubMed]

32. Guo J, Nguyen A, Banyard DA, Fadavi D, Toranto JD, et al. (2016) Stroma Vascular Fraction: A regenerative reality? Part 2: Mechanisms of regenerative action. J Plast Reconstr Aesthet Surg 69: 180-188. [PubMed]

33. Nguyen A, Guo J, Banyard DA, Fadavi D, Toranto JD, et al. (2016) Stroma vascular fraction: A regenerative reality? Part 1: Current concepts and review of the literature. J Plast Reconstr Aesthet Surg 69: 170-179. [PubMed]

34. Michalek J, Moster R, Lukac L, Proefrock K, Petrasovic M, et al. (2017) Stromal vascular fraction cells of adipose and connective tissue in people with osteoarthritis: A case control prospective multi-centric non-randomized study. Glob Surg 3: 1-9.

35. Berman M, Lander E (2017) A prospective safety study of autologous adipose derived stromal vascular fraction using a specialized surgical processing system. American J Cosmetic Surg 34: 129-142.

36. Shan HT, Zhang HB, Chen WT, Chen FZ, Wang T, et al. (2017) Combination of low-energy shock-wave therapy and bone marrow mesenchymal stem cell transplantation to improve the erectile function of diabetic rats. Asian $\mathrm{J}$ Andro 19: 26-33. [PubMed]

37. Jeon SH, Shrestha KR, Kim RY, Jung AR, Park YH, et al. (2016) Combination Therapy Using Human Adipose-derived Stem Cells on the Cavernous Nerve and Low-energy Shockwaves on the Corpus Cavernosum in a Rat Model of Post-prostatectomy Erectile Dysfunction. Urology 88: 1-9. [PubMed]

38. Berman M, Lander E (2015) Addendum. History of Adipose Derived Stroma Vascular Fraction Stem Cells. In: The Stem Cell Revolution, Indiana: Author House, pp.103-116.

39. Qui X, Fandel TM, Ferretti L, Albersen M, Orabi H, et al. (2012) Both immediate and delayed intracavernous injection of autologous adipose-derived stromal vascular fraction enhances recovery of erectile function in a rat model of cavernous nerve injury. Eur Urol 62: 720-727. [PubMed]

40. Lander E, Berman M, See J (2016) Stromal vascular fraction combined with shock wave for the treatment of peyronie's disease. Plast Reconstr Surg Glob Open 4: e631. [PubMed]

41. Ling G, Qui X, Fandel T, Banie L, Wang G, et al. (2011) Tracking intracavernously injected adipose-derived stem cells to bone marrow. Int J Impot Res 23: 268275. [PubMed]

42. Ortac M, Kucukergin C, Salabas E, Seckin S, Kadioglu A (2017) Effect of lowenergy shockwave therapy on angiogenic factors in the penile tissue of diabetic rats. Turk J Urol 43: 130-134. [PubMed]

43. Fandel TM, Albersen M, Lin G, Qiu X Ning H, et al. (2012) Recruitment of intracavernously injected adipose-derived stem cells to the major pelvic ganglion improves erectile function in a rat model of cavernous nerve injury. Eur Urol 61: 201-210. [PubMed]

44. Rosen RC, Riley A, Wagner G, Osterloh IH, Kirkpatrick J, et al. (1997) The International Index of Erectile Dysfunction (IIEF): a multidimensional scale for assessment of erectile dysfunction. Urology 49: 822-830. [PubMed] 